\title{
UMA ABORDAGEM CONCEITUAL SOBRE A HISTÓRIA MILITAR E FRONTEIRAS: A GUERRA DO CHACO E A QUESTÃO LETÍCIA1.
}

A conceptual approach to military history and frontiers: the Chaco war and the Leticia issue.

Un enfoque conceptual sobre la historia militar y las fronteras: la Guerra del Chaco y la Cuestión Leticia

Received: may/2020

Accepted: june/2020

Available online: june/2020

Fabio da Silva Pereira, Doutorando em História, Universidade Salgado de Oliveira (UNIVERSO), Brasil. E-mail: fabio.pereira.historia@gmail.com

Edna da Costa Silva, Mestranda em História, Universidade Salgado de Oliveira (UNIVERSO), Brasil. E-mail: ednamestrado@gmail.com

\begin{abstract}
Resumo: O presente artigo tem como objetivos abordar as diferentes concepções de fronteira e seus desdobramentos políticos e militares nos séculos XX e XXI. A abordagem teórica, no entanto, remonta ao século XIX, onde obras literárias forneceram concepções sobre a história e a geopolítica que nortearam as decisões políticas dos governantes, sobretudo na primeira metade do século XX, onde a Guerra do Chaco e a Questão Letícia serão o nosso alvo da pesquisa. $\mathrm{O}$ artigo destaca ainda que, além dos conflitos em paralelo à fronteira brasileira, ocorriam tensões políticas estabelecidas entre o Brasil e seus vizinhos por conta da rivalidade tradicional e da disputa pelo controle do poder regional. A investigação, pautada nos argumentos teóricos atuais ajudou, também, a demonstrar que os militares brasileiros do período foram os principais responsáveis pela intervenção da região Norte e do Centro-Oeste brasileiro considerando, para este propósito, a ocupação territorial e o controle dos limites terrestres, para manutenção da soberania nacional.
\end{abstract}

Palavras-chave : Guerra do Chaco, Questão Letícia, Fronteiras, História Militar.

\begin{abstract}
The present article aims to address the different conceptions of the border between States and its political and military developments in the 20th and 21 st centuries. The theoretical approach, however, dates back to the 19th century, where literary works provided insights into the history and geopolitics that guided the political decisions of rulers, especially in the first half of the twentieth century, where the Chaco War and the Leticia Question will be the our research target. The article also emphasizes that, in addition to the conflicts in parallel to the Brazilian border, there were political tensions established between Brazil and its neighbors due to the traditional rivalry and the dispute for control of regional power. The investigation, based on the current theoretical arguments, also helped to demonstrate that the Brazilian military of the period were the main responsible for the intervention of the North and the Brazilian
\end{abstract}

1 Uma versão anterior deste artigo foi apresentado no II Colóquio Internacional Movimentos: Trânsito e Memórias, da Universidade Salgado de Oliveira (UNIVERSO - Niterói - RJ), em 2019.

RBPPD/BRJPD | Vol. 2 | n. 2 | p. 87-108, 2020. 
Midwest considering, for this purpose, the territorial occupation and the control of the terrestrial limits, for the maintenance of national sovereignty.

Keywords: Chaco War, Leticia Question, Frontiers, Military History.

Resumen: Este artículo tiene como objetivo abordar las diferentes concepciones de frontera y sus desarrollos políticos y militares en los siglos XX y XXI. El enfoque teórico, sin embargo, se remonta al siglo XIX, donde las obras literarias proporcionaron información sobre la historia y la geopolítica que guiaron las decisiones políticas del gobierno, especialmente en la primera mitad del siglo XX, donde la Guerra del Chaco y la Pregunta Leticia serán Nuestro objetivo de investigación. El artículo también destaca que, además de los conflictos paralelos a la frontera brasileña, hubo tensiones políticas establecidas entre Brasil y sus vecinos debido a la rivalidad tradicional y la disputa por el control del poder regional. La investigación, basada en argumentos teóricos actuales, también ayudó a demostrar que los militares brasileños de la época fueron los principales responsables de la intervención de las regiones del norte y medio oeste de Brasil, considerando, para este propósito, la ocupación territorial y el control de los límites terrestres. , para mantener la soberanía nacional.

Palabras clave: Guerra del Chaco, Cuestión Leticia, Fronteras, Historia Militar.

\section{INTRODUÇÃO}

O presente artigo tem como objetivos fazer uma revisão bibliográfica e uma pesquisa documental para abordar as diferentes concepções de fronteira e seus desdobramentos políticos e militares nos séculos XX e XXI. A abordagem teórica, no entanto, remonta ao século XIX, onde obras literárias forneceram concepções sobre a história e a geopolítica que nortearam as decisões políticas dos governantes, sobretudo na primeira metade do século XX, onde a Guerra do Chaco (1932-1935) e a Questão Letícia (1932-1934) foram o nosso alvo da pesquisa. A concepção tradicional de fronteira aponta para a ideia de um limite entre Estados soberanos. Esse limite se faz respeitar e recorda a própria etimologia da palavra frontière, que vem do francês e aponta para um sentido bélico, ou seja, a fronteira está sendo guardada, protegida por uma praça armada (HOUAISS, 2001).

Quando se debate sobre fronteira encontramos implícito o princípio de territorialidade que, segundo Alberto do Amaral Júnior protege o interior do exterior, separa o nacional do estrangeiro que pode ser o amigo e o inimigo, mas que precisa manter o equilíbrio, onde "na origem da guerra e da paz, o princípio da territorialidade conduz à formação de um sistema internacional composto por territórios delimitados por fronteiras nacionais, que são reconhecidos como iguais" ( AMARAL JÚNIOR, 2008, p. 28 - 29). 
Entre as causas que promovem os conflitos armados e os alvos das conferências de paz, estão os problemas relacionados com a disputa por territórios de fronteiras. Diferente da concepção tradicional abordada, a historiografia mais recente ampliou a discussão sobre a temática e um leque de novos conceitos foi aberto, baseado inclusive, na observação das populações fronteiriças com ênfase na América Latina.

A fronteira como um lugar, conforme revelou Fábio Aristimunho Vargas, é um espaço entre os Estados soberanos onde elementos econômicos e culturais são compartilhados até criar uma identidade própria, porém múltipla e distinta do espaço original de pertencimento. Não se pensa em aculturação, sabe-se de sua impossibilidade sociológica, pois os indivíduos não perdem suas origens, mas de uma adaptação ao outro e ao espaço comum.

\begin{abstract}
"Mais do que o mero limite de um lugar, a fronteira seria ela mesma um lugar em si." [... A proximidade geográfica entre dois povos proporcionada pela fronteira permite a criação de um espaço comum onde naturalmente se desenvolvem relações de diversas ordens, onde a integração é um dado da vida, gerando uma cultura peculiar, sui generis, "fronteiriça", que se distingue na essência das culturas dos diversos países que conformam a fronteira. Não se trata, aqui, de "apropriação cultural", a adoção de elementos de uma cultura por um grupo cultural distinto. (VARGAS, 2017, p. 45 - 46)
\end{abstract}

Apesar do conceito de porosidade ser relativamente recente, entender fronteira como um local significa reconhecer uma construção histórica. As cidades fronteiriças da Amazônia possuem processos semelhantes de ocupação e exploração econômica. Esse é o caso de Tabatinga, no Brasil e Letícia, na Colômbia. Ambas têm nascimento indígena e exploração do caucho (DOMÍNGUEZ GÓMEZ, 1985) e da borracha (MENEZES 2009; OLIVEIRA 1995).

As mais recentes abordagens do tema fronteiras ainda trazem a questão da porosidade territorial. Trata-se de uma fronteira permeável, ou seja, aquela que, ao menos de forma pragmática é pulverizada de contatos diretos entre as comunidades locais de ambos os lados. Esse modelo de fronteira interessa aos Estados Nacionais porque permite o fluxo de suas mercadorias, pessoas e informações com o exterior. No entanto, todos os poros são selecionados e controlados pela ação dos agentes desse mesmo Estado a fim de promover uma regulamentação que o beneficie.

Nenhum laço se estabelece, nenhuma fronteira é ultrapassada sem passar antes pelo crivo atento das legislações aduaneiras, de imigração, de segurança alimentar, ambiental, saúde, 
etc. Trata-se, dessa forma, de "uma nova regulação e não de uma desregulação", termo com o qual se vulgarizou esse processo. "Um território fluido e poroso é a condição necessária para fazer parte do circuito das finanças mundiais no período atual” (ARROYO 2006, p. 6).

Ainda, de acordo com Vargas:

Por formalização de fronteiras designa-se o conjunto de atos emanados de autoridade competente, seja nacional ou internacional, com vistas a estabelecer as linhas de fronteiras, entendidas em sua acepção jurídico-política de limite do território, vinculando uma ou mais Estados, à luz do Direito Internacional (VARGAS, 2017, p. 31-32).

Contudo, para além do conceito concreto, o autor analisa outras formas de conceituação sobre fronteiras, explorando o conceito de espaço e não de limite, onde cita:

Se desenvolve uma comunidade peculiar, com costumes e práticas que, embora não neguem as origens nacionais diversas que lhe deram origem, são de certo modo delas diferenciadas. Busca-se com isso caracterizar a fronteira como um espaço de socialização, composto por uma comunidade imaginada dotada de identidade própria (VARGAS, 2017, p. 35).

Para Emerson Flávio Euzébio a globalização das relações sociais, políticas, econômicas e culturais exigem novas formas de abordagens e metodologias no tocante aos limites dos Estados e as fronteiras. Os fluxos de pessoas e informações constantes levaram à reformulação das rígidas leis que regulam o trânsito pelas fronteiras terrestres. Os novos arranjos diplomáticos combinados às demandas de produção internacional formularam o conceito da Porosidade Fronteiriça (EUZÉBIO, 2014). Logo, as fronteiras porosas são as regiões limítrofes, onde historicamente há um significativo fluxo de bens e informações. E que a partir de acordos jurídico-diplomáticos entre os Estados, que passam a fomentar o este tráfego, segundo os interesses dos países envolvidos.

\section{DESENVOLVIMENTO}

Corroborando com os argumentos apresentados por Vargas, Euzébio demonstra, através de uma análise estatística, o entrelaçamento das populações fronteiriças das cidade de Tabatinga (Brasil) e Letícia (Colômbia). Onde a conurbação do espaço criou uma nova identidade das populações. As singularidades desta região de fronteira viabilizam aspectos econômicos próprios da localidade, revelando a porosidade desta região de fronteira. Fato que justificou a criação da Zona de Regime Especial Fronteiriço para as localidades de Tabatinga e Letícia, em maio de 2008, ratificando através de ato formal jurídico o que antes ocorria ilegalmente. 
No Brasil, o exemplo de maior expressão é a cidade fronteiriça Tabatinga (AM) e sua cidade-irmã Letícia - Colômbia. Tabatinga passou a ser considerada estratégica, no contexto da segurança nacional. Com isso passou a receber incentivos, principalmente, no sentido da ocupação humana e militar.

Entretanto, o isolamento quase equidistante dos centros administrativos mais importantes, a falta de vias de comunicação terrestre, as tradições indígenas e as relações sociais e econômicas comuns, logo despertou a atenção para o emprego de novas metodologias nas relações diplomáticas em cidades gêmeas.

As relações jurídico-diplomáticas entre Brasil e Colômbia datam de 1907 com o Tratado de Bogotá que estabelecia os limites entre os países. Posteriormente, em 1922, o de Lozano-Salomón regulou a tríplice fronteira. A Questão Letícia é o nome dado ao conflito militar entre o Peru e a Colômbia iniciado entre agosto e setembro de 1932, tendo como objeto uma área do extremo sul do território colombiano fronteiriça ao Peru e ao Brasil e na qual se localiza a cidade de Letícia.

Figura 1: A Questão Letícia

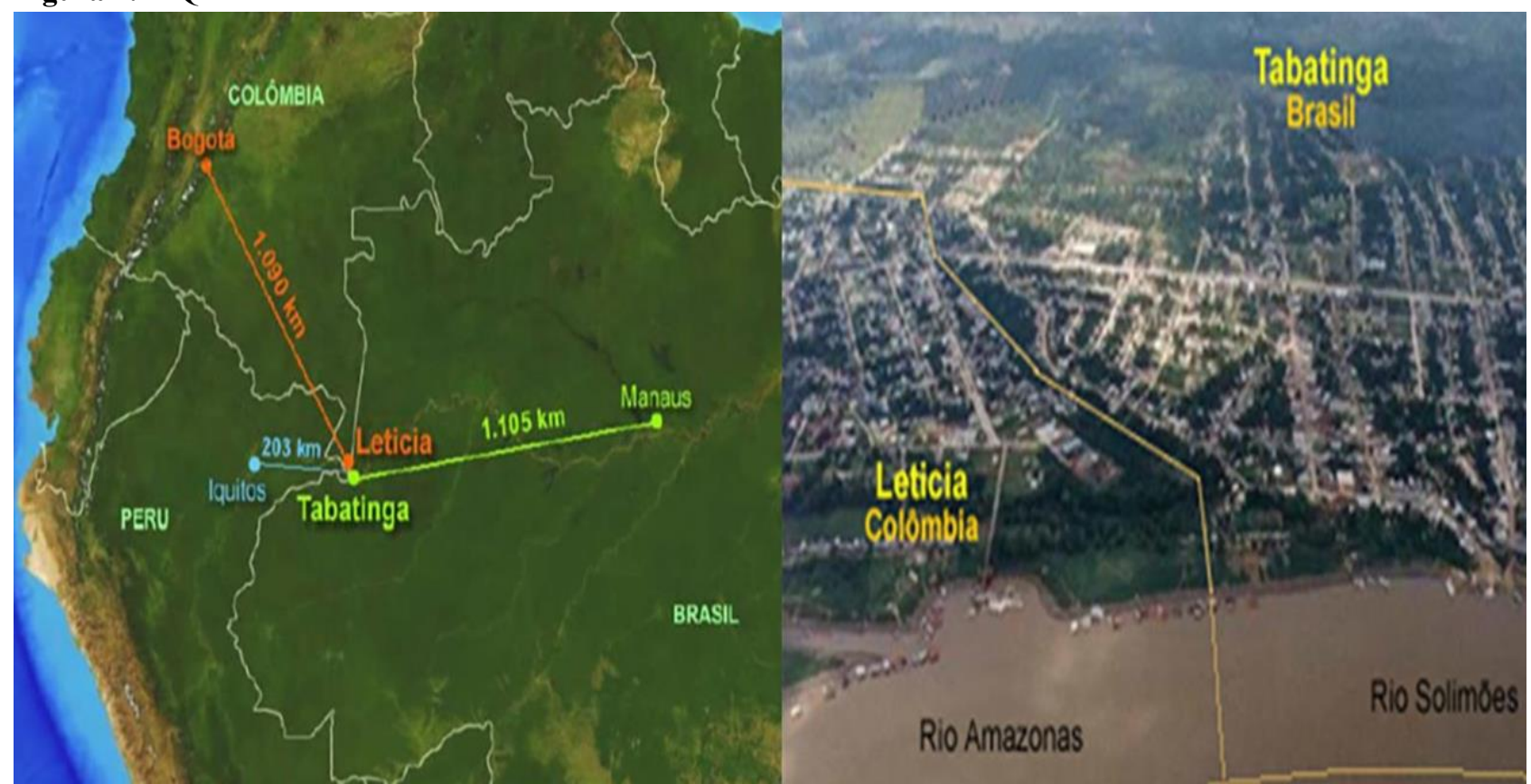

Fonte: Wanderley Junior (2018).

De acordo com Wanderley Júnior (2018), a resolução da questão deu-se em 1934, graças aos esforços de mediação do Brasil, sob o patrocínio da Liga das Nações. Como 
circunstâncias antecedentes, a área em questão vinha sendo reivindicada pela Colômbia e pelo Peru desde as guerras da Independência no século XIX. O impasse parecia ter sido resolvido em 1922, momento em que foi assinado um tratado que ficou conhecido como Salomón-Lozano, numa homenagem aos ministros que o negociaram, assegurando a posse do território à Colômbia.

No entanto, este tratado provocou fortes resistências entre os peruanos, que contestavam sua legitimidade por haver sido assinado durante o regime ditatorial do presidente Augusto Leguía. Na noite de 31 de agosto para $1^{\circ}$ de setembro de 1932, em operação não assumida oficialmente pelo governo de Lima, tropas peruanas tomaram de assalto a idade colombiana de Letícia, com apoio de artilharia pesada, hidraviões da força aérea e unidades da flotilha fluvial. Com esse ataque desencadearam-se ações de guerra local entre os dois países. Os dois países assinaram um novo acordo, em 25 de maio de 1933, chancelado pela Sociedade das Nações2, que constituiu uma Comissão Administradora, integrada por um oficial da Marinha do Brasil, por um diplomata da Espanha e por um oficial do exército dos Estados Unidos da América. Segundo Fernando Rodrigues “a comissão administrou o território por um ano, enquanto transcorria na cidade do Rio de Janeiro a conferência entre o representante diplomático peruano e colombiano, instalada em outubro de 1933, e presidida pelo embaixador brasileiro Afrânio de Melo Franco" (RODRIGUES, 2019, p. 36).

Já no final do século XX o Tratado de Cooperação da Amazônia, 1978 e a $1^{\circ}$ Declaração da Amazônia de 1989, em resposta a alguns estudos que propunham a gerência internacional sobre a floresta amazônica. Neste mesmo ano foram criadas a Zona Franca de Manaus e a cidade de Tabatinga foi transformada em Área de Livre Comércio, gozando de privilégios para a indústria e o comércio com reduções do imposto sobre a circulação de mercadorias e serviços (ICMS); imposto sobre os produtos industrializados (IPI); e demais taxas que incidem sobre a importação.

2 A Liga das Nações, ou Sociedade das Nações, criada ao término da Primeira Guerra Mundial (1914-1918), com sede em Genebra, na Suíça, foi a primeira organização internacional de escopo universal em bases permanentes, voluntariamente integrada por Estados soberanos com o objetivo principal de instituir um sistema de segurança coletiva, promover a cooperação e assegurar a paz futura. Os 26 artigos do Pacto da Liga foram incorporados à primeira parte do Tratado de Versalhes, tratado de paz entre as potências aliadas e associadas, de um lado, e a Alemanha derrotada, de outro, assinado em Versalhes em 28 de junho de 1919. A organização praticamente deixou de funcionar com a eclosão da Segunda Guerra Mundial em 1939, e foi oficialmente desativada em abril de 1946 (GARCIA, s./d, p. 1).

RBPPD/BRJPD | Vol. 2 | n. 2 | p. 87-108, 2020. 
$\mathrm{Na}$ Colômbia, foram criadas as Unidades Especiais de Desenvolvimento Fronteiriços somente no ano de 1995. A cidade colombiana de Letícia só recebeu este título em 1999, na qual desde então percebe-se um franco crescimento dos indicadores econômicos e sociais. No ano de 2008 o Brasil propôs a criação da Zona de Regime Especial fronteiriço - proposta que visa reduzir os embaraços burocráticos e facilitar a livre circulação de bens e serviços destinados ao uso familiar e cotidiano.

A despeito dos esforços para melhorar as relações comerciais e a qualidade de vida dos moradores das regiões fronteiriças. O Governo brasileiro manteve-se preocupado com o fator segurança nas fronteiras a Constituição Federal de 1988 dedica atenção especial ao tema e o associa a riscos externos e internos, tais como: contrabando, imigração, segurança e saúde. Com isso, as políticas relativas à ocupação territorial da Amazônia e o desenvolvimento sustentável das cidades fronteiriças foram atualizadas atendendo as demandas do século XXI. A proteção dos recursos amazônicos está presente em legislações recentes ou atualizações de programas já iniciados, por exemplo: Política de Defesa Nacional/2005; Estratégia de Defesa Nacional/2008; Livro Branco de Defesa Nacional/2010; Programa Calha Norte/2004.

Portanto, fronteira porosa é um conceito que se traduz em uma nova abordagem, que visa integrar as cidades situadas nas zonas fronteira aos centros administrativos e ao modo de produção de capital internacional, oficializando e regulando relações que já se desenvolviam de modo tradicional. Sem, contudo, abandonar a velha doutrina de rigidez dos limites nacionais. Criase um modelo híbrido, onde se seleciona uma determinada localidade e nela se desenvolve o modelo de porosidade, enquanto nas demais áreas limítrofes a forma de ocupação é tradicional: presença militar, rigidez no controle dos fluxos, pouco ou nenhum trânsito de bens ou pessoas, além de baixa densidade populacional.

Com o avanço da historiografia, é mister a apresentação de uma bibliografia renovada que lance novos esclarecimentos sobre o desenvolvimento das nações Latino Americanas, mas qualquer estudo sobre o tema seria vago se não abordasse em primeiro lugar os fatos que 
permitiram a configuração cartográfica dos estados que aí estão, bem como os aspectos jurídicos fundamentais para resguardar os referidos territórios. Desta forma, o diálogo da História com pesquisadores de outras ciências, como Fábio Aristimunho Vargas e Emerson Flávio Euzébio.

A revisão de literatura e o aprofundamento na apresentação de conceitos que tratam da problemática do estabelecimento das fronteiras dos vinte países da américa latina são abordados por Vargas, que reuniu inúmeras informações tanto de contextos históricos, como questões jurídicas e conceituais acerca da complexa demarcação dos limites entre os citados territórios.

Uma vez ampliado o conhecimento através da análise da obra de Vargas, o diálogo com o artigo de Euzébio permite uma reflexão mais otimizada do tema tratado por este autor, que propõe o conceito que define a fronteira como um local de permeabilidade no cenário econômico global, caracterizado pelo entrelaçamento das nações através de acordos e estreitamento de relações. Onde o fluxo de bens, serviços e pessoas corresponde a uma dinâmica natural para a atualidade. Sobre o tema, o autor defende que "para os Estados Nacionais, acentuar a porosidade territorial de suas fronteiras faz parte da atual conjuntura econômica globalizante e visa facilitar os fluxos com o exterior" (EUZÉBIO, 2014, p.110).

Disputas por territórios fronteiriços, quando não resolvidos pela diplomacia dos Estados envolvidos, originam conflitos armados. Iniciando uma evidente disputa pela soberania em territórios requeridos como áreas de pertencimento das nações em conflito. Por soberania, Norberto Bobbio define:

\footnotetext{
O conceito fundamental de onde se há de partir é que, se a SOBERANIA (V.), ou monopólio internacional da força, é o poder de garantir, em última instância, a eficácia de um ordenamento jurídico, sendo por isso a garantia da manutenção de relações pacíficas dentro do Estado, ela é também, por outro lado, a causa da guerra nas relações entre os Estados (Kant) (BOBBIO, 2004, p. 1089).
}

Antes de se proceder a uma análise sobre alguns desses eventos, principalmente na América Latina, é preciso uma abordagem, mesmo que breve, sobre o que se entende por guerra e as mudanças que ocorreram nesse sentido até chegar ao atual pensamento de seus principais intérpretes. 
Carl Von Clausewitz, foi um militar estrategista prussiano que viveu no fim do século XVIII e primeiras décadas do século XIX, escrevendo a obra "Da Guerra" em 1832, usada largamente nos círculos de estudiosos sobre o tema. Durante sua experiência defendeu, em suas célebres frases que “a guerra é a continuação da política por outros meios”. Na época de Clausewitz o fazer história era pela vertente política e não cultural. O autor é contemporâneo de Leopold von Ranke, historiador alemão que forneceu o modelo de história científica tradicional, narrativa, política usando apenas fontes oficiais sem problematizações.

As principais preocupações do teórico prussiano estavam voltadas para as guerras da Revolução Francesa e napoleônicas, principalmente sob a ótica dos países ameaçados por elas. Eram guerras políticas que envolviam sociedades. Essa poderia ser a razão das improváveis, porém, reais e sucessivas vitórias francesas. A partir dessas observações baseadas nas experiências vivenciadas Clausewitz se expressou da seguinte forma:

\footnotetext{
"Nova participação do povo nos grandes negócios de Estado; essa participação, por sua vez, resultou, em parte, do impacto que a Revolução teve sobre condição interna de cada Estado e, por outro lado, do perigo que a França representou para todos. Será sempre assim no futuro? A partir de agora, cada guerra na Europa será travado com todos os recursos do Estado e, portanto, deverá ter como motivo apenas as grandes questões que afetam o povo?" (KEEGAN, 2006, p. 44).
}

De origem prussiana, foi um dos primeiros pensadores a defender a ideia de uma guerra total, ou seja, aquela que recruta todos os meios disponíveis por um Estado: seus homens em condições de lutar, seus meios materiais, sua economia e, em uma esfera superior, a política. Se Clausewitz produz "Da Guerra" já em um contexto de relativa paz, sua obra vai repercutir nas próximas gerações como na I Guerra Mundial. O teórico responsável pelo "manual de guerra" mais referenciado pelos especialistas militares do século XX, possivelmente sofreu influência tanto das obras de Maquiavel como também de Sun Tzu, ambas intituladas A Arte da Guerra, onde o objeto de estudo era tratado de modo pragmático. O militar germânico defendeu em sua obra que a guerra fomentava a própria política, dando movimento e dinâmica a desdobramentos políticos, ideia essa defendida em inúmeras frases célebres do autor, dentre as quais vale também citar que "a arte da 
guerra, no seu ponto máximo, é a política, mas a política que trava batalhas, e não a política que escreve notas" (CLAUSEWITZ, 2005, p. 292).

Opondo-se a esse viés teórico, encontramos o atual trabalho de John Keegan, Uma História da Guerra, de 2006. Apesar de não ter a mesma experiência do campo de combate, era admirador dos estudos sobre a guerra e se tornou professor das principais academias de História Militar, tendo se tornado um dos maiores especialistas sobre o tema. Keegan diz que a guerra mesmo estando ligada à política, economia e a diplomacia, vai muito mais além porque os homens que a fazem no campo de combate são diferentes dos demais, eles são movidos por seus costumes e tradições, suas próprias culturas. (KEEGAN, 2006, p. 16). Keegan discorda sobre ser a guerra uma continuação da política por outros meios porque a guerra é anterior e existe desde que o homem está sobre a terra. Entre as principais críticas está a que o militar prussiano não tinha preparo filosófico, atendo-se apenas na linha bélica.

\begin{abstract}
A guerra não é a continuação da política por outros meios. (...) O pensamento de Clausewitz está incompleto. Ele implica a existência de Estados, de interesses de Estados e de cálculos racionais sobre como eles podem ser atingidos. Contudo a guerra precede o Estado, a diplomacia e a estratégia por vários milénios. A guerra é quase tão antigo quanto o próprio homem e atinge os lugares mais secretos do coração humano, lugares em que o ego dissolve os propósitos racionais, onde reina o orgulho, onde a emoção é suprema, onde o instinto é rei. (KEEGAN, 2006, p. 18)
\end{abstract}

A guerra não é sempre regular e os homens em combate nem sempre obedecerão as estratégias dos gabinetes. Por vezes ela foi e será sem escrúpulos e selvagem, obedecendo as características culturais dos povos e de seus guerreiros. Clausewitz representava o homem símbolo dos exércitos regulares contra a falência da organização anterior estruturada no dom da nobreza em fazer a guerra com sua cavalaria e obedecendo ao sistema de vassalagem ainda medieval.

Para o historiador inglês, o militar alemão deixou de observar o fenômeno da guerra nos cantos do mundo, onde outros fatores diferentes dos políticos entram em ação. É o caso da Ilha de Páscoa onde havia uma espécie de política teocrática que vivia de forma pacífica, mas que acabou iniciando um período de guerra endêmica que destruiu sua cultura e sua gente. Então o princípio usado de que a guerra é uma continuação da política não se aplica, não funciona. Na Ilha de Páscoa 
foi usada o conceito de guerra total no sentido de que toda aquela sociedade entrou em guerra e todos também morreram. A guerra endêmica, atestada pelos navegadores europeus que lá chegaram, não era uma continuação da política baseada no líder que descendia dos deuses e que gerava o maná, o equilíbrio da vida na ilha. Quando essa guerra foi instaurada, ela levou a política, a cultura e a própria vida ao fim, como escreveu Keegan:

\begin{abstract}
Maná e tabu fixavam um equilíbrio entre os papéis e chefe, guerreiro e membro de clã, com benefício para os três; se suas interrelações podem ser chamadas de 'política' da vida polinésia, então a guerra não era sua continuação. A guerra, quando chegou, em sua forma 'verdadeira' àquele cantinho da Polinésia chamado Ilha de Páscoa, revelou-se o fim primeiro da política, depois da cultura, e finalmente quase da própria vida (KEEGAN, 2006, p. 51).
\end{abstract}

Outro exemplo usado por Keegan foi sobre os zulus africanos. Em uma nação pastoril e tranquila, a ascensão de seu líder militar Shaka, os organizou em regimentos violentos com novas armas, vocação para matar e destruir, em nome e defesa de seu povo particular. Milhares de mortos e membros de tribos, perderam seus território e membros, fugindo para longas distâncias. Além da destruição dos vizinhos, outra consequência foi a desorganização sócio econômica dos próprios zulus, pois os guerreiros ficavam no serviço militar por longo tempo, até os 40 anos, sem poder casar e, portanto, fora da sociedade. Após a morte de Shaka, seus guerreiros continuaram a usar seu modelo. Posteriormente, chegaram a adquirir armas de fogo, mas nunca conseguiram se adaptar e continuaram a usar sua arma letal que tanto os fizeram temíveis - a lança de estocar. Esse foi outro modelo de Clausewitz que, segundo Keegan, não funcionou. Observe sua citação:

\begin{abstract}
Shaka era um clausewitziano perfeito. Criou um sistema militar para servir e proteger um modo de vida particular, o que fez com eficácia impressionante. A cultura zulu, ao dar destaque aos valores guerreiros, ao ligar esses valores à preservação de uma economia pastoril e ao prender a energia e a imaginação dos membros mais dinâmicos da comunidade numa servidão militar estéril até bem depois da maturidade, negou a si mesma a chance de evoluir e adaptar-se ao mundo circundante. Em suma, a ascensão e a queda da nação zulu oferecem uma advertência terrível às deficiências da análise de Clausewitz (KEEGAN, 2006, p. 56)
\end{abstract}

Tais exemplos usados pelo historiador inglês para criticar as ideias de Clausewitz estão situados em diferentes tempos e espaços. No entanto as análises chegam a um tempo mais próximo com foi o caso da destruição causada pela I Guerra Mundial. Segundo John Keegan, o prussiano foi 
o ideólogo da Primeira Guerra. Ele diz que o século XIX havia uma cultura de fazer uma sociedade guerreira onde todos estariam preparados para pegar em armas. Um século de relativa paz, mas que se preparava ideologicamente para alcançar uma sociedade de guerreiros que estariam prontos para lutar até não conseguir mais. A prosperidade alcançada foi esgotada em uma destruição sem precedentes que se consumiu em quatro anos. Complementando o pensamento historiográfico, as ideias de Clausewitz sobre a organização e a relação do Estado e do regimento, não poderiam se adaptar a todas as sociedades pois guerra não se fecha ou se resume com exclusividade a política porque o homem é também um ser cultural.

Tendo se tornado um dos maiores especialistas dos estudos da guerra na atualidade o historiador John Keegan, falecido em agosto de 2012, desenvolvendo oposição às ideias de Clausewitz, formulou também o conceito de que a guerra ocuparia um papel de protagonista tanto na sociedade quanto na política, onde afirmava que "a história escrita das sociedades é em grande medida, uma história das guerras” (KEEGAN, 2006 p. 492).

Com a análise das obras de John Keegan e Carl Von Clausewitz, percebe-se a grandiosidade da contribuição destes dois historiadores para com os estudos de história militar, cada qual a seu tempo em realidades distintas, como já elucidadas neste artigo. Contudo, cabe ressaltar que tanto em história militar como em outros campos da história, novas abordagens e discussões sobre seus objetos, ainda produzirão debates e entendimento ampliado sobre as guerras e a história de modo geral. Em conformidade com os argumentos de Vainfas, onde cita:

\footnotetext{
Mas talvez o campo dessa nova história militar (NHM) seja mesmo um dos que mais promete novidades, quer teoricamente, quer no tocante a seus objetos de estudo, como veremos a seu tempo. Em contrapartida, é possível dizer que a história militar já nasceu velha, na medida em que a guerra é tão antiga quanto a história da humanidade e, sobretudo, porque a guerra foi o grande objeto dos historiadores na aurora da história, enquanto gênero narrativo, pelo menos no mundo ocidental (CARDOSO e VAINFAS, 2012 p. 114).
}

Um das causas que figuram no seio da humanidade, levando as sociedades em diferentes tempos-espaços a guerra, estão as disputas por territórios. Essas experiências nos ligam às fronteiras, aos limites que, como já estudados, definem o espaço de soberania dos Estados. Nesse 
ínterim, o acontecimento de um passado recente, nos leva ao estudo de caso sobre disputa por fronteiras, que provocou um conflito armado entre dois Estados latino-americanos - a Bolívia e o Paraguai, nos anos de 1932 a 1935, a Guerra do Chaco.

A região do Chaco Boreal é uma planície entre os citados países que permaneceu como fronteira indecisa. Segundo o conceito expresso por Michel Foucher (2005) é o tipo de fronteira que não coincide com a ocupação humana ou com o controle do Estado. Os problemas fronteiriços entre a Bolívia e o Paraguai têm ligações com sua história desde a fase colonial, como criticou o general Waldomiro Castilho de Lima, ao produzir um estudo sigiloso sobre A Questão do Chaco Boreal, em 1934. Desde o século XIX, as questões sobre o domínio da região não foram resolvidas o que os levou ao conflito. Os autores oscilam sobre as causas principais e citam as dificuldades econômicas do Paraguai e a necessidade de passagem da Bolívia para o mar através do rio Paraguai e a bacia do Prata.

Silveira (2009, p. 650) afirma que o Chaco Boreal (Figura 2) é uma das regiões do grande "território do Chaco, no centro da América do Sul, com cerca de 170.000 Km2, limitado a leste pelo rio Paraguai, a oeste pelo Pilcomayo e, ao norte, pelas encostas da serra de Santa Cruz, no centro da América do Sul”.

Figura 2: Chaco Boreal

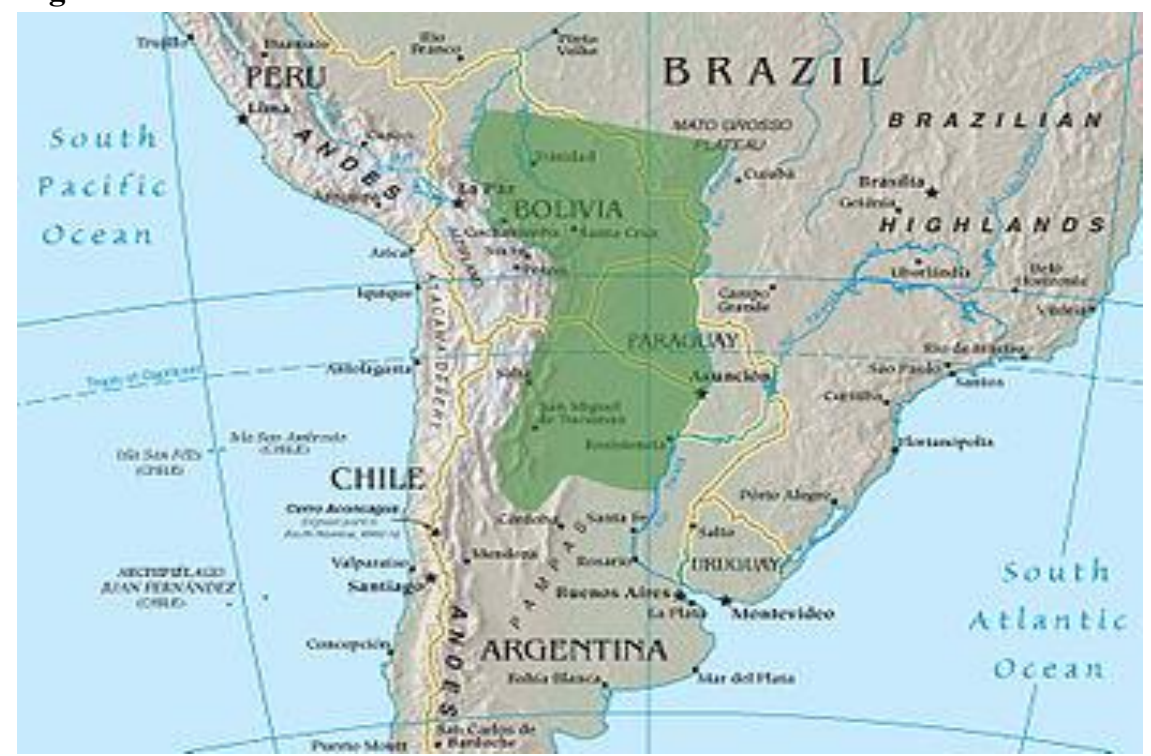

Fonte: Chaco (2019). 
A guerra do Chaco foi "um conflito travado entre Bolívia e Paraguai durante os anos de 1932 e 1935. As fronteiras não terem sido bem definidas pelo colonialismo espanhol [...] durante o processo de independência do que viria a ser a Bolívia e o Paraguai” (ELTZ, 2015, p. 23).

Nesse sentido, o relatório do general Waldomiro Castilho de Lima (Brasil, 1934, p. 1), aponta que a colonização hispânica permitiu "não haverem alguns países ainda traçado definitivamente as suas fronteiras, mantendo discussões e pendências diplomáticas que se eternizam e que já tem causado muito sangue e muitas questões políticas agitadas”.

Após a delimitação espacial da área a ser estudada, faz-se necessário compreender os antecedentes que culminaram no conflito. Segundo o mesmo relatório (BRASIL, 1934, p. 3), junto a formação do Paraguai e com ela os 'direitos baseados no princípio de 'uti-possidetis2' sobre o Chaco Boreal [...] deixando, assim, às duas nacionalidades, a semente da discórdia e das lutas..."

A fase das operações é denominada pelo general Waldomiro (BRASIL, 1934) como "hostilidades", por causa da dinâmica bélica envolvendo ações isoladas de destacamentos, com destaque para a tomada do Fortin Boquerón pelos paraguaios, "não houve uma ação geral bem combinada que parecesse obedecer a um plano de guerra devido a escassez dos efetivos dos beligerantes" (BRASIL, 1934, p. 37).

O relatório do general Waldomiro assim sintetiza o ano de 1932:

\begin{abstract}
Vimos como as hostilidades conduziram em 1932 os quase beligerantes a uma generalização da luta, com o emprego de todas as armas de que dispunham e sem declaração formal do estado de guerra. Dessas operações salientou-se a supremacia das forças paraguaias melhor preparadas e situadas próximas as suas bases de reabastecimento, ao passo que as bolivianas se achavam longe... [...] Os paraguaios na sua ofensiva conquistaram grande parte do terreno chaquenho mas, com a chegada dos reforços bolivianos a situação se estabilizou, paralisando-se aquela ofensiva (BRASIL, 1934, p. 37-38, grifo dos autores).
\end{abstract}

Para além dos protagonistas estão os demais Estados vizinhos com interesses sobre a hegemonia na região. Brasil e Argentina viveram momentos de cooperação e, principalmente de rivalidades para garantir sua influência e interesses regionais.

Para Mário Travassos a política brasileira era indissociável da continental o que justificava a ação de sua diplomacia junto aos beligerantes do Chaco. Dialogando com essa ideia 
estava o próprio Exército que analisava a questão sob a ótica da geopolítica. Os principais problemas apontados para o Brasil se referiam ao vazio demográfico no interior e nas fronteiras, a vulnerabilidade dos países vizinhos e o despreparo do próprio Brasil diante dessa situação. Para exemplificar, Travassos aponta uma Argentina melhor organizada na economia e na interligação com sua rede de transportes no início do século XX. No caso do Brasil a rede fluvial estava melhor qualificada.

O reconhecimento das debilidades fronteiriças levou o Brasil, na década de 1930, a inspecionar seus limites com os vizinhos, momento concretizado nas expedições de inspeção de fronteiras do general Cândido Rondon, por determinação do presidente Washington Luís. Importava assegurar a soberania nas extremidades implicitamente ameaçadas por tensões ou vazios demográficos, como era o caso da região amazônica. Junto a esse movimento, a instalação do telégrafo para integrar o interior, permitiu que o Brasil desenvolvesse ações diplomáticas fundamentais na Guerra do Chaco e na Questão Letícia, o que também colaborou para manter-se no diálogo pela hegemonia continental.

Para Mário Travassos ainda o domínio sobre o triângulo formado pelas cidades de Santa Cruz de La Sierra, Cochabamba e Sucre era fundamental para tornar o Brasil à frente da Argentina. O triângulo estava nas fronteiras com o Mato Grosso e sua importância geopolítica estava na comunicação com a bacia do Prata e com a região amazônica. A solução estava na construção de uma ferrovia ou de uma rede fluvial que comunicasse tais cidades bolivianas com os portos brasileiros. Os debates aumentaram as rivalidades com a Argentina, onde o chanceler Saavedra Lamas foi o principal articulador da maior parte do processo das negociações de paz entre 1935 e 1938.

Na Guerra do Chaco a Argentina, devido ao seu envolvimento econômico com o Paraguai, o apoiava. O Brasil, apesar da neutralidade, ficava mantinha-se mais próximo da Bolívia devido a sua ação diplomática. De forma diferente o Paraguai ainda guardava resquício de sua derrota na Guerra da Tríplice Aliança, acusando o Brasil de ser imperialista e expansionista.

RBPPD/BRJPD | Vol. 2 | n. 2 | p. 87-108, 2020. 
O estudo sigiloso do Acervo Pessoal do general Waldomiro Castilho de Lima3

(BRASIL, 1934), salientava a tensão Brasil-Argentina mostrando os perigos de uma invasão de ambos pelo Mato Grosso, o que exemplificou com a montagem da empresa "Matte Larangeira" nas proximidades do Forte de Coimbra, o que representava um obstáculo à segurança nacional (RODRIGUES, 2018, p. 39). Como solução Waldomiro sugeriu a reorganização e o reforço das tropas brasileiras na região e no próprio Forte de Coimbra.

O general chega a elaborar um esboço tático onde simula uma ocupação do território nacional por uma força de invasão estrangeira. As tropas invasoras poderiam se beneficiar dos meios de transportes de empresas de navegação e ferroviárias, que desenvolvem suas atividades na região, e formavam uma vasta rede de comunicação que se estendia desde o oeste do Rio Grande do Sul e Paraná até as regiões do Triângulo Mineiro e sul de Minas Gerais. O relatório do general Waldomiro destaca a importância do conflito para as políticas de segurança nacional e, principalmente, serve como alerta para o Estado Brasileiro deveria ficar vigilante e prontificar uma rápida resposta contra um eventual agressão estrangeira.

Com o objetivo de detalhar a questão do Chaco, o General Waldomiro não observou apenas os fatos contemporâneos ao desenvolvimento do estudo, buscou os antecedentes históricos

3 Waldomiro (nome original) ou Valdomiro Castilho de Lima nasceu no Rio Grande do Sul no dia 15 de janeiro de 1873. Iniciou sua carreira militar em janeiro de 1890 quando sentou praça no regimento da Guarnição de Fronteira de Missões (RS). Ingressou na Escola Tática e de Tiro de Rio Pardo (RS) no final do mesmo ano, sendo incorporado em dezembro, já como cadete, ao $28^{\circ}$ Batalhão de Infantaria. combatendo as forças rebeldes envolvidas na Revolução Federalista, guerra civil que até 1895 manteve conflagrados os estados do Rio Grande do Sul, Santa Catarina e Paraná. Em abril de 1898 transferiu-se para a Escola Militar do Brasil, na Praia Vermelha (RJ), então Distrito Federal. Eleito e reeleito deputado estadual no Rio Grande do Sul em 1904 e 1908, cumprindo os mandatos até 1913. Em junho de 1920, matriculou-se em uma das primeiras turmas da Escola de Estado-Maior do Exército e aí assistiu ao curso ministrado pela Missão Militar Francesa que, sob a chefia do general Maurice Gustave Gamelin, prócer da primeira equipe de instrutores franceses. Em 1923 foi preso pelo governo de Arthur Bernardes (1922 - 1926) por simpatizar-se com os tenentes da Revolução de 1922, permanecendo na Ilha de Trindade, no Oceano Atlântico até 1925. Participou da Revolução de 1930 ao lado das tropas de Getúlio Vargas, este casado com Darci, sobrinha da Waldomiro. Possuidor de fortes ligações familiares, foi reincorporado à ativa em 28 de julho de 1932 no posto de general-de-divisão e dividiu com o general Pedro Aurélio de Góis Monteiro o comando das forças que combateram os revoltosos que estavam ao lado dos paulistas, tendo sido o responsável pela cobertura da frente sul. Após o armistício dos revoltosos, foi nomeado pelo presidente da República Governador Militar e Interventor do Estado de São Paulo, permanecendo até julho de 1933. Reintegrado às suas funções militares no dia 26 de outubro de 1933 como inspetor do $1^{\circ}$ Grupo de Regiões Militares. Realizou o Curso de Informações para generais em 1935, tendo se classificado em primeiro lugar. Em consequência, Waldomiro Lima foi designado para estagiar no Estado-Maior do Exército francês. Em dezembro de 1936, Valdomiro Lima assumiu o comando da $1^{\text {a }}$ Região Militar, no Rio de Janeiro. Em disputas internas com o general Góis Monteiro pela nomeação à chefia do Estado-Maior do Exército, foi novamente preso por quatro dias em 1937 , sendo acusado de traição. Faleceu em fevereiro de 1938, vítima de uma trombose cerebral (MAYER, s./d.).

RBPPD/BRJPD | Vol. 2 | n. 2 | p. 87-108, 2020. 
que poderiam subsidiar um justo entendimento sobre o assunto. Nesta linha de pesquisa, a investigação retrocedeu não só até o sistema de colonização espanhola como também a todos os fatos históricos subsequentes e que, de alguma maneira, corroboraram para o conflito permanente na região.

O estudo feito sob a direção do general Waldomiro demonstra como ponto de partida para todo conflito, o próprio modelo de colonização espanhola, onde, segundo a pesquisa, tinha como única preocupação o recebimento de tributos e não as lides entre os adelantados, mesmo sendo eles os conquistadores e desbravadores autorizados pela Coroa a explorar a colônia, lidando com situações geográficas desconhecidas dos espanhóis e oportunizando espaços que em momento futuro iriam gerar as contestações.

O estudo avança no tempo e faz um inventário minucioso das teses que justificaram a reclamação do território do Chaco pelas partes mais interessadas, sobretudo, Paraguai e Bolívia. Há ainda uma avaliação subjetiva sobre um tipo de caráter impetuoso atribuído ao Paraguai em suas ações em prol da conquista do Chaco, mesmo com a argumentação da chancelaria paraguaia qualificando-a. Em outro ponto, fica demonstrada a preocupação do General Waldomiro com assuntos pertinentes à própria soberania do território brasileiro onde é reforçada a ideia de aparelhamento de tropas, instalações (com atenção especial para o Forte Coimbra) e ampliação de recursos de defesa na região precavendo-se de um possível ataque por parte dos paraguaios.

Situação interessante, também, é a caracterização do papel da Argentina frente ao conflito do Chaco, onde fica evidenciada sua articulação política em favor do Paraguai por se tratar de uma área de influência dos argentinos e de interesse econômico. Alguns trechos do documento justificam a conclusão apresentando com os seguintes argumentos:

Para a Argentina, esse país é um prolongamento dos seus imporios (sic) comerciais e seu território constitue (sic) indiretamente um elemento geográfico tributário da sua própria economia política. [...] Por aí se vê como o governo apoia e oficialisa (sic) as tendências (sic) da opinião pública em considerar o território do Paraguai como prolongamento dos domínios argentinos. (LIMA, 1934, p.10-11). 
São enumerados as tratativas que antecederam ao conflito Paraguai x Bolívia, que envolveram não só a chancelaria dos países envolvidos como também dos países vizinhos apoiados, até mesmo pela Liga das Nações. O embate entre os países não pode ser evitado e tampouco as inúmeras baixas no campo de batalha. O Estudo faz um manifesto descritivo das ofensivas de batalha e dos excessos de guerra aviltados pelo Paraguai.

Com uma linha de trabalho contundente e que prima pela preservação dos limites, fronteiras e interesses do Brasil, o Estudo também faz uma longa explanação das situações de risco pontuando a maneira como devem ser salvaguardadas as fronteiras do país próximas ao Chaco.

\section{CONSIDERAÇÕES FINAIS}

A análise dos textos consultados para a construção deste artigo, que privilegiou alguns autores e obras consagradas na historiografia sobre fronteiras e guerras, demonstrou a elasticidade que o conceito de fronteira ganhou com o passar dos anos, sobretudo, no período entre os séculos XIX e XXI, passando pela mais remota abordagem onde a designação fronteira representa, tão somente, limite entre estados, sendo origem de conflitos por demarcação de áreas de interesse econômico, cultural ou religioso, definindo-a como limite de território, lugar, fator de segurança e caracterizando todos os tipos de fronteira. O conceito explicitado neste documento através da análise do artigo de Emerson Flávio Euzébio argumentou sobre a integração de regiões fronteiriças através do que define como porosidade de fronteira. Dessa forma, a ideia de elasticidade do conceito de fronteira é a sinergia da integração e da diferença político-econômico e cultural, reverberando essas características na vertente político-militar.

Como exemplos dessa elasticidade, temos as questões históricas relacionadas ao casus beli na Amazônia Ocidental e no Chaco na década de 1930 e a gradativa mudança durante a década de 1990 após diversas negociações. Nesse ponto, a geopolítica internacional ainda colhe frutos do ideal de globalizante e estabelece como condição de desenvolvimento um maior entrosamento entre 
as nações, estabelecido através de acordos econômicos, diminuição de restrições em fronteiras e sempre orientados pela necessidade de maior fluxo de pessoas, mercadorias e serviços.

A definição de porosidade utilizada a designa como característica de territórios nacionais que proporciona e favorece sua relação com o exterior, considerando uma legislação específica que ampare a ampliação do fluxo econômico e social. Isso proporcionou uma característica única para cada ponto da fronteira, onde as características regionais somam-se aos fatores políticos, econômicos e sociais naquele setor, livrando a generalização das características homogêneas dos estudos do século XIX, em que a fronteira marcava o fim, o limite. A Guerra do Chaco envolveu esses antigos conceitos, gerando a guerra entre estados e a atenção de vários países pelo seu desenrolar, como o Brasil, a Argentina e os Estados Unidos. No que tange aos conflitos armados sobre a disputa por fronteiras, a Guerra do Chaco não está isolada, vários outros conflitos de natureza e com objetivos semelhantes foram travados. Para se compreender a essência da guerra comparamos o pensamento de Clausewitz com John Keegan.

Foi relevante observar que o Brasil acompanhou os eventos e formulou documentos que revelaram a preocupação, naquele contexto de tensões latino-americanas, com a guarda e a integração de suas próprias fronteiras. Autores como Mário Travassos e o Gen Waldomiro mostraram as debilidades do Brasil frente aos seus vizinhos e a disputa com a Argentina, apoiadora do Paraguai na Guerra que ora se desenvolvia pelo território do Chaco Boreal.

Assim, as possíveis respostas ficaram nos grandes projetos de ligação litoral-sertão para preencher o vazio demográfico e na melhor proteção das fronteiras. Para tanto o desenvolvimento da rede fluvial na Amazônia brasileira e a integração pelas estradas de ferro seriam fundamentais para proporcionar a segurança estratégica das próprias fronteiras e facilitar a integração com os países de interior e com o Pacífico, como foi o caso da Bolívia e do Peru.

RBPPD/BRJPD | Vol. 2 | n. 2 | p. 87-108, 2020. 


\section{REFERÊNCIAS}

AMARAL JÚNIOR, Alberto do. Introdução ao Direito Internacional Público. São Paulo: Atlas, 2008. p. 28-29.

BRASIL. Ministério da Guerra. A Questão do Chaco Boreal (Estudo Sigiloso). Rio de Janeiro: Inspetoria do $1^{\circ}$ Grupo de Regiões Militares, 1934.

BRASIL. Ministério da Guerra. Synthese das informações colhidas sobre a guerra bolivianoparaguaya, no chaco boreal, e seus antecedentes (relatório secreto). Rio de Janeiro: Imprensa do EME, 1935.

BRASIL. Poder Judiciário. Supremo Tribunal Federal. Constituição da República Federativa do Brasil. Brasília: Supremo Tribunal Federal, Secretaria de Documentação, 2017. 518 p. Disponível em: http://www.stf.jus.br/arquivo/cms/legislacaoConstituicao/anexo/CF.pdf. Acesso em 01 abr. 2018.

BOBBIO, Norberto, MATTEUCCI, Nicola e PASQUINO, Gianfranco. Dicionário de Política. Brasília: UNB, 1998.

CARDOSO, Ciro Flamarion; VAINFAS, Ronaldo. (Orgs). Novos Domínios da História. Rio de Janeiro: Elsevier, 2012.

CLAUSEWITZ, Carl Von. Da Guerra. Tahyu, 2005.

DE LIMA. Castilho Waldomiro. A Questão do Chaco Boreal. Rio de Janeiro: Estado Maior do Exército, 1934.

DOMÍNGUES GÓMEZ, Camilo Augusto. Amazonía Colombiana: visión general. Bogotá: Banco Popular. 1985.

ELTZ, André Henrique. Ocultação indígena na Guerra do Chaco (1932-1935). Revista Labirinto, v. 23. Porto Velho: UNIR, jul-dez 2015, pp. 22-64. 
EUZÉBIO, Emerson Flávio. A porosidade territorial na fronteira da Amazônia: as cidades gêmeas Tabatinga (Brasil) e Letícia (Colômbia). Cuadernos de Geografía. Revista Colombiana de Geografía. Bogotá, v. 23, p. 109-124.

GARCIA, Eugênio Vargas. Sociedade das Nações (verbete). Rio de Janeiro: CPDOC, s./d. Disponível em: https://cpdoc.fgv.br/sites/default/files/verbetes/primeirarepublica/LIGA\%20DAS\%20NA\%C3\%87\%C3\%95ES.pdf. Acesso em: 12 jun. 2020.

HOUAISS, Antônio. Dicionário Houaiss da Língua Portuguesa. Rio de. Janeiro, Ed. Objetiva, 2001.

KEEGAN, John. Uma história da guerra. São Paulo: Companhia das Letras, 2006. p. 492.

MAYER, Jorge Miguel. Valdomiro Castilho de Lima (verbete). Rio de Janeiro: CPDOC, s./d. Disponível em: http://www.fgv.br/cpdoc/acervo/dicionarios/verbete-biografico/valdomiro-castilhode-lima. Acesso em: 12 jun. 2020.

MENEZES, Maria Lúcia Pires. Pequenas cidades em faixa de fronteira na Amazônia: o caso de Tabatinga e Benjamin Constant. In, Oliveira, José Ademir de (Org.): Cidades brasileiras: territoriedades, sustentabilidade e demandas sociais. vol. 1, Manaus: EDUA, 2009.

OLIVEIRA, José Aldemir de. As cidades amazônicas: a ilusão da busca. AGB Boletim Amazonense de Geografia n ${ }^{\circ}$ 2, 1995.

RODRIGUES, Fernando da Silva. Fronteiras como desafio histórico para o Exército: da geopolítica de Mário Travassos à Defesa do território brasileiro na primeira metade do século XX. In: Análise estratégica, volume 10 (4). Brasília CEEEx, set-nov 2018. Disponível em: http://ebrevistas.eb.mil.br/index.php/CEEExAE/article/download/1839/1487/. Acesso em: $1^{\circ}$ fev. 2019.

RODRIGUES, Fernando da Silva. Conflitos contemporâneos na América do Sul e as tensões nas fronteiras do Brasil. In: Análise estratégica, volume 11. Brasília CEEEx, dez-fev 2019. Disponível em: http://ebrevistas.eb.mil.br/index.php/CEEExAE/article/download/2117/1711/. Acesso em: 10 jun. 2020.

RBPPD/BRJPD | Vol. 2 | n. 2 | p. 87-108, 2020. 
SILVEIRA, Helder Gordim da. A visão militar brasileira da Guerra do Chaco: projeção geopolítica e rivalidade internacional na América do Sul. Antíteses, v. 2, n. 4. Londrina: UEL, jul.-dez 2009, pp. 649-667.

VARGAS, F. A. Formação das fronteiras latino-americanas. Brasília: FUNAG, 2017.

WANDERLEY JUNIOR, H. I. Questão Letícia: análise da atuação militar brasileira no conflito colombo peruano (1932- 1934). Revista de Trabalhos Acadêmicos, nº 17. Niterói: Universidade Salgado de Oliveira, 2018. 